\title{
Transaction
}

\section{Stereocomplexation in the Solution Spun PLLA / PDLA Blend Fibers}

\author{
Jun Jae Lee ${ }^{* 1}$, Jae-Chang Lee ${ }^{* 2}$, and Hideki Yamane ${ }^{* 2}$ \\ ${ }^{* 1}$ Graduate School of Science and Technology, Kyoto Institute of Technology, \\ Matsugasaki, Sakyo-ku, Kyoto 606-8585, Japan \\ ${ }^{*}$ Center for Fiber \& Textile Science, Kyoto Institute of Technology, \\ Matsugasaki, Sakyo-ku, Kyoto 606-8585, Japan
}

\begin{abstract}
Solution-spun PLLA/PDLA blend fibers were obtained by the laboratory size spinning machine. The fibers obtained were drawn to various ratios at temperatures ranging from 80 to $140^{\circ} \mathrm{C}$ and subsequently annealed at $200^{\circ} \mathrm{C}$ under tension. Solution-spun fibers were highly crystallized during the coagulation process in the solution spinning and only the a-form homo-crystal of PLLA and PDLA were detected. Drawing of the fiber at temperatures between $80^{\circ} \mathrm{C}$ and $160^{\circ} \mathrm{C}$ did not promote the stereocomplexation between PLLA and PDLA. The drawn fiber seems to have two homo-crystal phases, one easily transformed to the streocomplex upon annealing at an elevated temperature and the other stayed either homo-crystal or melted during annealing and froze into the amorphous phase. The fibers drawn to higher ratios at higher temperatures, which showed a large melting peak of the homo-crystal at higher temperature region, kept homo-crystal phase even upon annealing at $200^{\circ} \mathrm{C}$. On the other hand, the fibers drawn to lower ratios at lower temperatures, which show the single melting peak of homo-crystal at a lower temperature region, changed the structure from oriented homo-crystal to the oriented stereocomplex upon annealing. Due to the small content of oriented stereocomplex crystal and larger content of unoriented amorphous phase, the fibers annealed at an elevated temperature have fairly poor mechanical property.
\end{abstract}

(Received 15 January, 2010 ; Accepted 27 February, 2010)

\section{Introduction}

Poly(L-lactic aicd) (PLLA) has a melting temperature $T_{m}$ of about $180^{\circ} \mathrm{C}$. However, its thermal properties are not high enough for use as ordinary structural materials. Most synthetic polymers for the synthetic fibers, such as nylon 66, nylon 6, and PET have a melting point higher than $200^{\circ} \mathrm{C}$. Hence, enhancement of heat-resistance or thermal property of PLLA is a matter of concern when PLLA is utilized for various applications including industrial application. One of the most effective methods for increasing the thermal property of PLA is to make stereocomplex-type crystal with a $T_{m}$ above $230{ }^{\circ} \mathrm{C}$, much higher than the $T_{m}$ of pure PLLA. Stereocomplextype PLA has been found in a mixture of the equimolar blend of PLLA and poly(D-lactic acid) (PDLA) [1]. Since the early investigation by Ficher et al. [2], several groups have studied the crystallization behavior of stereocomplex-type PLA [3-7]. A lot of studies have been carried out to produce PLA fibers with different kinds of spinning processes, such as dry, wet and melt spinning processes [8-12]. Takasaki et al. reported the high-speed melt spinning of PLLA/PDLA blends with various blend ratios [13]. They found that the PLLA/PDLA 50/50 blend high-speed spun fiber obtained under high spin-line tension contained a certain amount of stereocomplex crystal, and the annealing gave a fiber mainly consisting of highly oriented stereocomplex crystal. Tsuji et al. performed the solution spinning of complex fibers from a mixed solution of PLLA/PDLA [14]. Tensile strength of the solution spun complex fibers was very low, and could not be drawn at high temperatures. Furuhashi et al. [15] demonstrated that the higher-order structure and mechanical properties of PLLA/PDLA blend melt spun fibers. They found that the drawn PLLA/PDLA blend fibers have two phases of the homo crystal of PLLA or PDLA, one, which shows a lower melting temperature, is small and deformed homo-crystal consisting of fairly well mixed PLLA and PDLA chains and the other, which shows a higher melting temperature, is more perfect homo-crystal consisting of poorly mixed PLLA and PDLA chains. Although the former easily transformed into the stereocomplex upon annealing, the latter just melted and re-crystaliized into homo-crystal. Their result indicates that the simple melt mixing has its limit to produce the PLLA/PDLA blend which crystallizes into the stereocomplex without forming any trace of the homo-crystal. Masaki et al. [16] has developed a special 
melt blending technique to compound the PLLA/PDLA blend which consistently forms the stereocomplex without showing any trace of homo-crystal. They speculated that the formation of block copolymer of Land D-lactic acid due to the transesterification would enhances the stereocomplexation in the blend specially prepared. These back ground strongly suggests that the mixing state of PLLA and PDLA chains in the blend is important role to obtain the thermally stable poly(lactic acid) fibers. Although it is a disadvantage to prepare the polymer blend in a solution state in both the industrial and ecological points of view, it is interesting to investigate the structure and various physical properties of the PLLA/PDLA blend fibers from the blend with a well mixed state may be expected.

In this study, the equal amounts of PLLA and PDLA were mixed at a solution state and wet-spun into fine fibers. Changes in the thermal and mechanical properties and the higher-order structure of the wet-spun PLLA/ PDLA blend fibers in the spinning, drawing and annealing processes were investigated.

\section{Experimental}

\subsection{Materials}

The polymers used in this study were PLLA (Lacty, medical grade, weight average molecular weight, $\mathrm{Mw}=$ $2.26 \times 10^{5} \mathrm{~g} / \mathrm{mol}, \mathrm{OP}=98.5 \%$ ee) and PDLA (PURAC, $\mathrm{Mw}=3.35 \times 10^{5} \mathrm{~g} / \mathrm{mol}$, OP $=99.9 \%$ ee). They were stored under vacuum at ambient conditions.

\subsection{Preparation of the solution spun fibers}

PLLA and PDLA were separately dissolved in chloroform $\left(\mathrm{CHCl}_{3}\right)$ as a solvent to be $15 \mathrm{wt} \%$ solutions under constant stirring at ambient conditions for 24 hours. The equal amount of the polymer solutions prepared were mixed together with vigorous stirring for 30 minutes, and then the mixed solutions were left for 30 minutes until the solution spinning process. Solution spinning of stereocomplex-type PLA was carried out using a laboratory size solution-spinning system. The polymer solution was extruded through the spinneret of $0.6 \mathrm{~mm}$ in inner diameter into the methanol coagulation bath at a throughput rate $0.125 \mathrm{ml} / \mathrm{min}$. The take up speed for the solution spun fiber was $8 \mathrm{~m} / \mathrm{min}$. The fibers obtained were dried in vacuo for at least 3 days.

The fibers thus prepared were drawn and annealed at various temperatures with a drawing machine with two sets of rolls and a heating chamber. The fibers were drawn to $3 \sim 11$ times at temperatures ranging from 80 to $160^{\circ} \mathrm{C}$. Annealing of the drawn fibers was conducted at $200^{\circ} \mathrm{C}$ under tension (7.5MPa) in an electric tube furnace, which leads to 1.2 times drawing.

\subsection{Measurements and observation}

\subsubsection{Morphological study}

Morphological study was performed by using a SEM (KEYENCE Corp. VE-7800). The samples were goldcoated on an aluminum stage prior to observation.

\subsubsection{Wide-angle X-ray diffraction (WAXD)}

WAXD patterns were obtained at room temperature using a nickel-filtered $\mathrm{CuK} \alpha$ radiation with a wave-length of $0.1542 \mathrm{~nm}$, from a Rigaku RINT 2100-FSL system sealed beam X-ray generator operating at $40 \mathrm{kV}$ and 20mA. WAXD patterns were recorded using a point collimated beam and a flat-plate film holder.

\subsubsection{Thermal property}

Thermal property of the fibers was determined with a DSC, Shimadzu DSC-50 in a $\mathrm{N}_{2}$ atmosphere. About $2 \mathrm{mg}$ of fiber sample cut into small pieces was placed in an aluminum pan and the DSC measurements were performed to $250^{\circ} \mathrm{C}$ at a heating rate of $10^{\circ} \mathrm{C} / \mathrm{min}$. Melting and crystallizing temperatures were determined from the maximum of the endothermic and the exothermic peaks, respectively.

\subsubsection{Mechanical Property}

Mechanical property of the fibers was evaluated using a tensile testing machine (CATY-500BH, YONEKURA Co. Ltd.) at a cross-head speed of $20 \mathrm{~mm} /$ min at a room temperature. A specimen gauge length of $20 \mathrm{~mm}$ was used. The results obtained were averaged over ten samples for each condition.

\section{Results and discussion}

\subsection{Solution spinning and drawing of PLLA/ PDLA blend fibers}

\subsubsection{Morphology of the fibers}

$10 \mathrm{wt} \%$ mixed solution showed a poor spinnability, while $20 \mathrm{wt} \%$ solution was not extruded through the spinneret smoothly. Because of these results, the rest of the experiments were carried out for $15 \mathrm{wt} \%$ solutions and the fibers about $100 \mu \mathrm{m}$ in diameter were easily obtained.The SEM images of the solution spun fibers are shown in Fig. 1(a). The as spun fiber has an irregular rough surface. A lot of scratched marks in the fiber direction are observed. This may be due to the difference in the rate of exchange of solvent and non-solvent in the coagulation bath at the time of coagulation. Further it is likely to be caused by the gelation of the solution in the coagulation bath due to the formation of the stereocomplex crystallites before complete coagulation. 

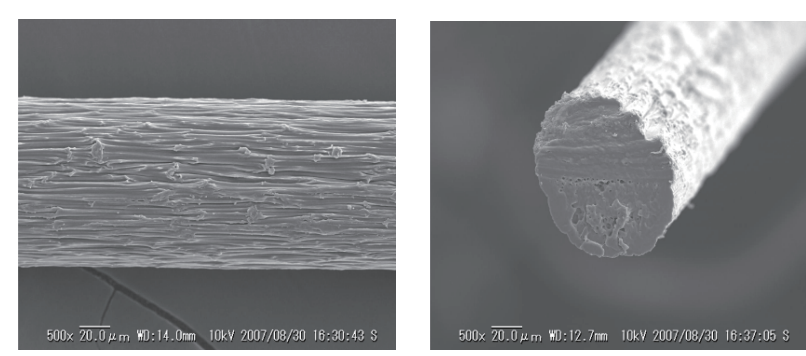

(a) As-spun
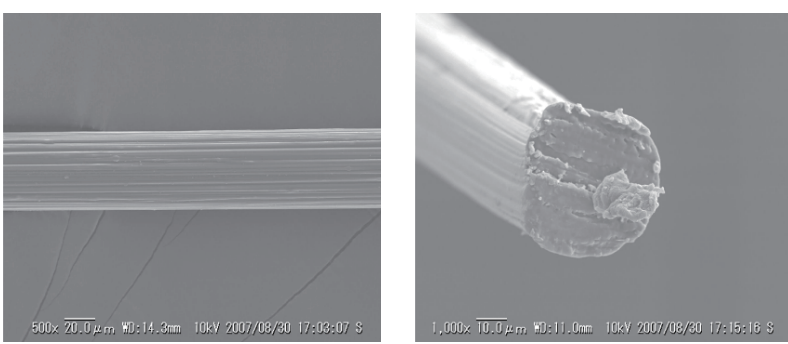

(b) Drawn to 5 times at $100^{\circ} \mathrm{C}$

Fig. 1 Surface and cross-section of the as-spun and drawn fibers.

The cross section of the as spun fiber has a circular shape and no void was observed. After the drawn of the fiber at $100^{\circ} \mathrm{C}$ became quite smooth surface.

Drawing of the fibers was possible at a temperature ranging from 80 to $160^{\circ} \mathrm{C}$. The fiber tended to break in the Drawing process at the temperature lower than $80^{\circ} \mathrm{C}$ the surface of the fiber became quite smooth after the drawing as shown in Fig. 1(b).

\subsubsection{Thermal properties of the drawn PLA fibers}

DSC thermograms of as spun and drawn fibers are shown in Figs. 2 and 3. As-spun fiber only shows a single melting peak of PLLA and PDLA homo-crystal around $180^{\circ} \mathrm{C}$ and that of the stereocomplex around $230^{\circ} \mathrm{C}$ without indicating any trace of the crystallization peak at lower temperature region. This strongly suggests that the high degree of crystallization occurred during the coagulation process of the fiber in the coagulant. This is contrary to the DSC curves of PLLA/PDLA blend meltspun fibers reported by Furuhashi et al., which shows a large exothermic crystallization peak as well as a clear glass transition [15]. Fig. 2 shows the change in the DSC curves of the fibers drawn to various draw ratios at $100^{\circ} \mathrm{C}$. The single melting peak of PLLA and PDLA homocrystal observed in the curve of as spun fiber changed into double peaks after drawing. The peak at higher temperature tended to be stronger and to shift to the higher temperature with increasing draw ratio. Further the melting peak of the stereocomplex observed around $225^{\circ} \mathrm{C}$ seems to be slightly larger with increasing draw ratio without shifting the peak temperature to a large extent.

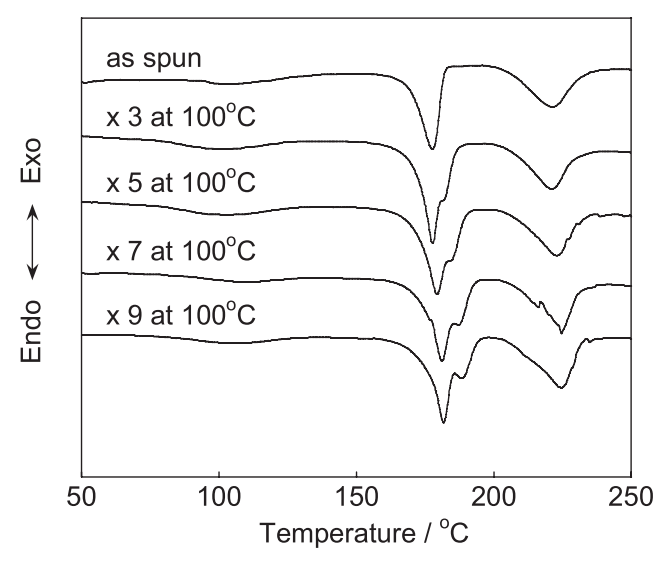

Fig. 2 DSC thermograms of the fibers drawn to various ratios at $100^{\circ} \mathrm{C}$.

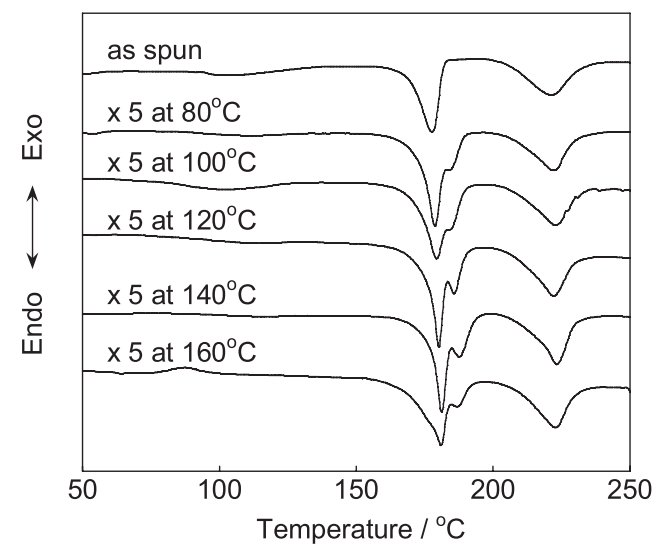

Fig. 3 DSC thermograms of the fibers drawn to 5 times at various temperatures.

Similar tendency was also noticed when the fiber was drawn to 5 times at various temperatures. Fig. 3 shows the change in the DSC curves of the fibers drawn to 5 times at various temperatures. Melting of the homocrystal was observed for the drawn fibers as double endothermic peaks and the peak at the higher temperature tended to be larger and to shift slightly to the higher temperature region. It should be noticed for the fiber drawn at $160^{\circ} \mathrm{C}$ that a small crystallization peak is observed around $85^{\circ} \mathrm{C}$. This may be due to the drawing at an elevated temperature where the less ordered and small crystallites melt and were frozen as an amorphous state without crystallizing.

\subsubsection{Higher-order structure of the drawn PLA fibers}

The macromolecular chains of PLLA and PDLA in the homo-crystal have left- and right- handed helical conformations, respectively, with $10_{3}$ helix and pseudoorthorhombic crystals (a-form) in conformation are contained in a unit cell dimensions of $\mathrm{a}=1.06 \mathrm{~nm}, \mathrm{~b}=$ $0.61 \mathrm{~nm}, \mathrm{c}=2.88 \mathrm{~nm}, \alpha=\beta=\gamma=90^{\circ}[16,17]$. On the other hand, the crystal structure of the PLA stereocomplex was proposed by Okihara et al [18]. The 


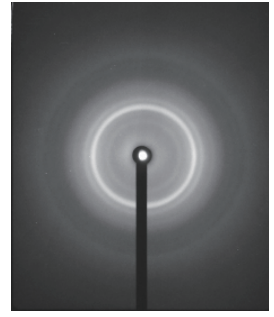

As-spun

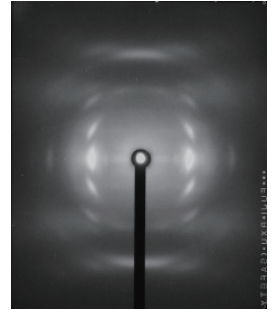

x 3 at $100^{\circ} \mathrm{C}$

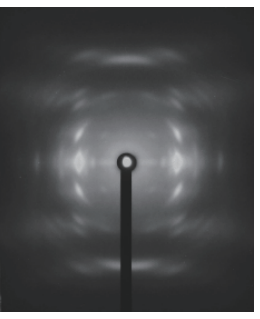

x 7 at $100^{\circ} \mathrm{C}$

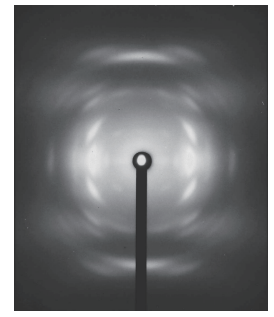

x 5 at $100^{\circ} \mathrm{C}$

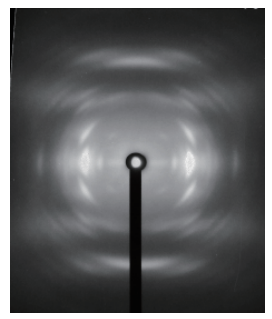

x 9 at $100^{\circ} \mathrm{C}$
Fig. 4 WAXD patterns of as-spun fibers and fibers drawn at $100^{\circ} \mathrm{C}$ to various ratios.
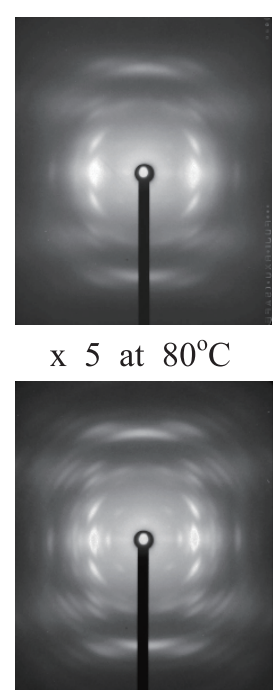

x 5 at $140^{\circ} \mathrm{C}$ x 5 at $80^{\circ} \mathrm{C}$

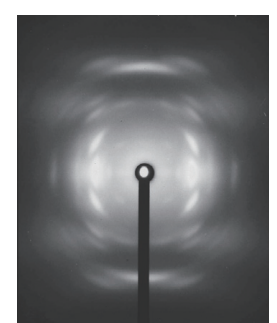

x 5 at $100^{\circ} \mathrm{C}$

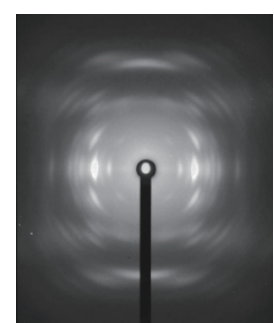

x 5 at $160^{\circ} \mathrm{C}$

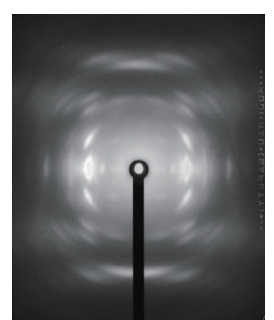

x 5 at $120^{\circ} \mathrm{C}$
Fig. 5 WAXD patterns of the fibers drawn to 5 times at various temperatures.

lattice containing a PLLA or PDLA chain with a $3_{1}$ helical conformation has the shape of an equilateral triangle, which is expected to form equilateral-triangleshaped single crystals of the PLA stereocomplex. The stereocomplex crystal system is the conformations of the helical chains shrinking slightly to $3_{1}$ repeats and form a triclinic crystal structure with a unit cell of $\mathrm{a}=\mathrm{b}=0.916$ $\mathrm{nm}, \mathrm{c}=0.870 \mathrm{~nm}, \alpha=\beta=109.2^{\circ}$, and $\gamma=109.8^{\circ}$.

Figs. 4 and 5 show the changes in the WAXD pattern of PLLA/PDLA blend fibers with drawing process. As spun fiber (Fig. 4) shows a strong Debye-Scherrer ring at $2 \theta=16^{\circ}$ identified as (200) of the $\alpha$-form crystal indicating a high degree of crystal which does not have any preferred orientation. As already mentioned in the previous section, this is contrary to the melt spun PLLA/ PDLA fiber which shows only an amorphous halo [15].

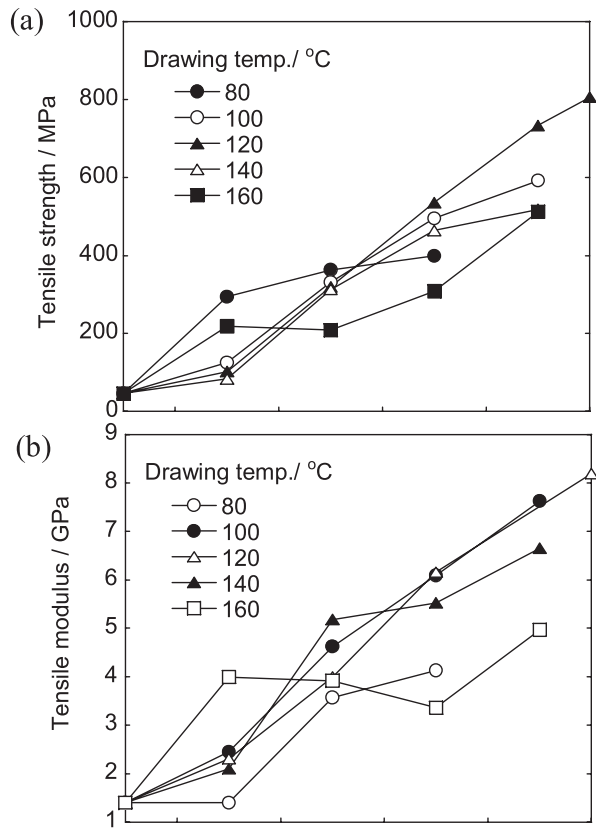

(c)

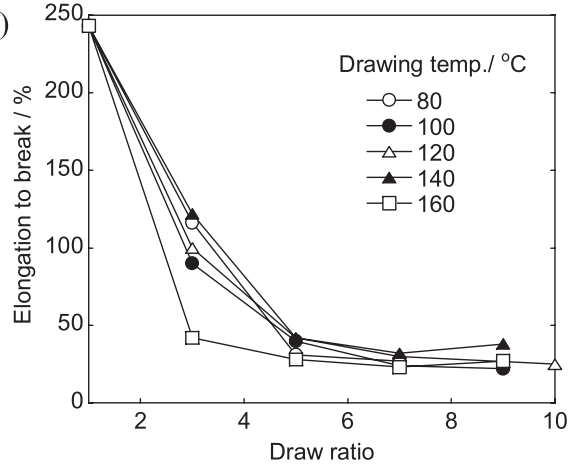

Fig. 6 Mechanical property of the drawn fibers.

(a) Tensile strength, (b) tensile modulus, and (c) elongation to break.

WAXD pattern changed to the arcs after drawing and the 1 st to 3rd layer lines are clearly observed. The degree of crystalline orientation did not show clear dependence on the draw ratio when the fiber was drawn at $100^{\circ} \mathrm{C}$. The reflections from the stereocomplex were not clearly observed when the fiber was drawn less than 5 times at $100^{\circ} \mathrm{C}$. However the reflections at $2 \theta=12$ and $21^{\circ}$ on the equator attributable to (100), (010), (-110) and (110), $(-120),(-210)$ of the stereocomplex crystal $[19,20]$ tended to appear slightly at higher draw ratios. These reflections became much noticeable with increasing drawing temperature as shown in Fig. 5. However, the reflection from the homo-crystal was still strong. This indicates that the drawn fibers consist of the $\alpha$-form homo-crystal with c-axis oriented to the fiber direction.

Although the DSC curves of the as spun and drawn fibers show a large endothermic melting peak of stereocomplex around $225^{\circ} \mathrm{C}$, the fiber drawn in this study did not show any strong indication of the stereocomplex formation in the WAXD pattern. Probably the endothermic peak observed around $225^{\circ} \mathrm{C}$ in the DSC 
curve is the melting of the stereocomplex re-crystallized from the amorphous chains and homo-crystal melted during the DSC heating scan.

\subsubsection{Mechanical Property of the drawn fibers}

Figs. 6(a) (c) show the mechanical property of the drawn fibers. These data indicate a general tendency that the tensile strength and modulus increased and the elongation to break decreased monotonically with the draw ratio irrespective of the drawing temperature. The highest tensile strength and modulus, $800 \mathrm{MPa}$ and 8.2 $\mathrm{GPa}$, respectively were obtained for the fibers drawn to 10 times at $120^{\circ} \mathrm{C}$. However when the drawing at $160^{\circ} \mathrm{C}$ did not improve the mechanical property as expected and the elongation at break drastically decreased even when it was drawn to 3 times. This may be due to the spherulitic crystallization of the fiber drawn to the lower draw ratio at an elevated temperature.

\subsection{Annealing of the PLLA/PDLA blend fibers}

\subsubsection{Thermal property of the annealed fibers}

Masaki et al. [16] reported that the melt-spun PLLA/ PDLC blend fibers show a broad crystalline WAXD pattern when the fibers were drawn at a limited condition, although the most fibers still remain in amorphous state even after drawing. The fibers which show a crystalline WAXD pattern could be annealed under tension at a temperature as high as $180^{\circ} \mathrm{C}$ and the crystalline structure was completely transferred to that of the stereocomplex after annealing.

The annealing of the solution spun and drawn PLLA /PDLA blend fibers prepared in this study was achieved as high as $200^{\circ} \mathrm{C}$, irrespective of the draw ratio or the drawing temperature and the fiber tended to break in the annealing process at higher temperatures. This is due to the high degree of crystal of the solution spun fibers. DSC heating curves of PLLA/PDLA fibers annealed at $200^{\circ} \mathrm{C}$ after drawing to 5 times at various temperatures and after drawing to various draw ratios at $100^{\circ} \mathrm{C}$ are shown in Figs. 7 and 8, respectively. It is a general tendency that the fibers annealed at an elevated temperature show a clear glass transition around $60^{\circ} \mathrm{C}$ and a quite large crystallization peak around $95^{\circ} \mathrm{C}$. This result indicates that the fiber annealed at an elevated temperature has fairly low degree of crystal. The homo-crystal in the fiber melted and a part of the homo-crystal phase transformed into the stereocomplex in the annealing process. However the other part did not transformed into the stereocomplex and stays either the homo-crystal or the amorphous due to the low crystallization rate of the homo-crystal. The fibers previously drawn to 5 times at temperatures higher than $100^{\circ} \mathrm{C}$ showed two melting peaks of the homo crystal

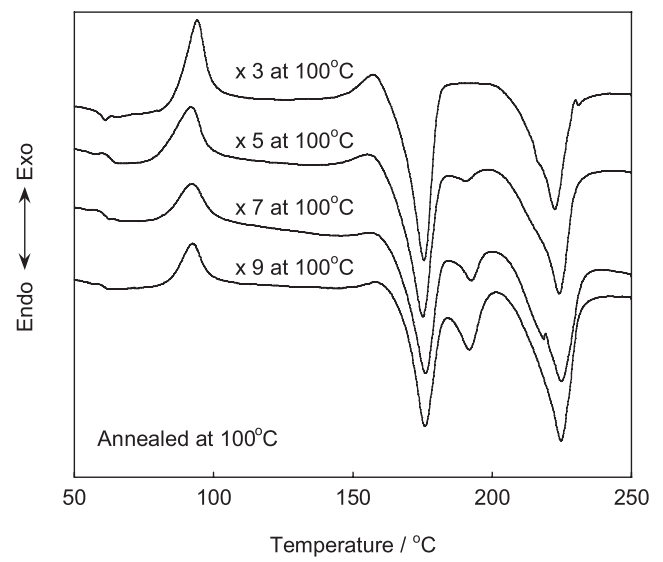

Fig. 7 DSC curves of the annealed fibers drawn to various ratios at $100^{\circ} \mathrm{C}$ in advance.

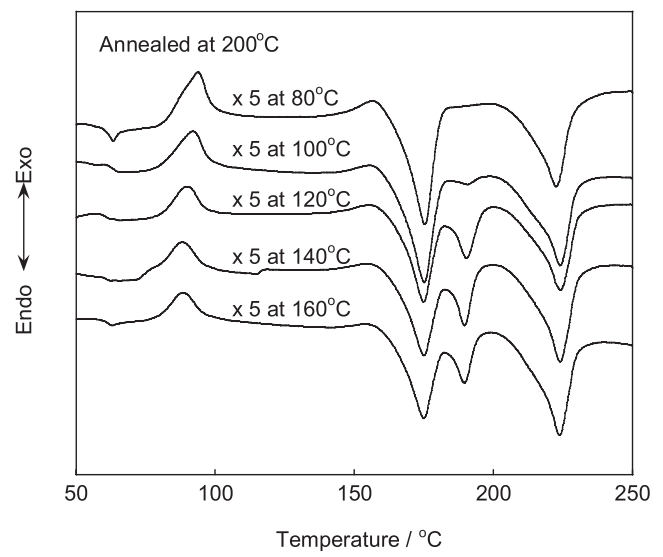

Fig. 8 DSC curves of the annealed fibers drawn to 5 times at various temperatures in advance.

consecutively at 175 to $190^{\circ} \mathrm{C}$. The peak observed around $190^{\circ} \mathrm{C}$ tended to be larger with increasing drawing temperature (Fig.7) and with draw ratio (Fig.8). Furuhashi et al. [15] suggested that the drawn and annealed fibers seem to have two homo crystalline phases. One with a higher melting temperature is a homo crystal phases of pure PLLA and PDLA poorly mixed. This leads to the remaining of homo crystal even after annealing at an elevated temperature. The other with a lower melting temperature is a homo crystal of PLLA or PDLA mixed fairly well so that it can be transferred into the stereocomplex easily after annealing at a high temperature. Their results would suggest the possibility to have higher content of the stereocomplex phase when the PLLA/PDLA solution spun fibers previous drawn to lower draw ratio at a lower temperature. This can be confirmed with the aid of WAXD measurements.

\subsubsection{Higher-order structure of the annealed PLA fibers}

Fig. 9 shows the WAXD pattern of the PLA fibers annealed at $200^{\circ} \mathrm{C}$ after drawing to 5 times at various temperatures. As shown in Fig. 5, the fibers drawn to 5 times at 80 and $100^{\circ} \mathrm{C}$ show oriented and fairly diffuse 
crystalline reflections. These WAXD patterns completely transferred into that of the oriented stereocomplex upon annealing at $200^{\circ} \mathrm{C}$. Although the fibers drawn at higher temperatures also show the reflections from the stereocomplex, those from the homo-crystal are still clearly observed and tended to be stronger with increasing drawing temperature. The WAXD patterns of the fibers annealed at $200^{\circ} \mathrm{C}$ after drawing to various draw ratios at $100^{\circ} \mathrm{C}$ are shown in Fig.10. The annealed fibers drawn to $3 \sim 5$ times previously show only the WAXD reflections from the stereocomplex. However the fibers drawn to higher ratios show the reflections from both the homocrystal and the stereocomplex.

These results support the discussion given in 3.2.2.
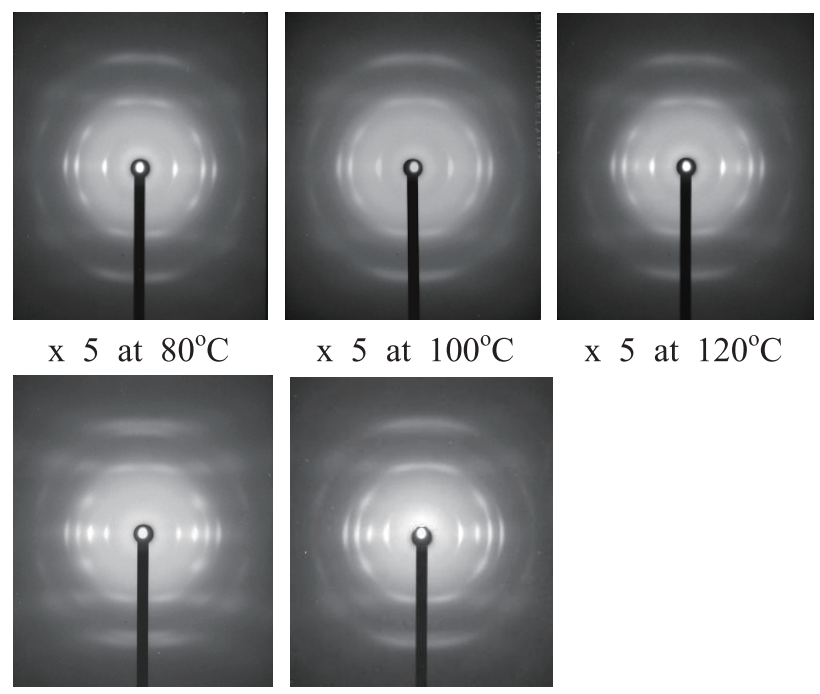

x 5 at $120^{\circ} \mathrm{C}$

x 5 at $140^{\circ} \mathrm{C}$

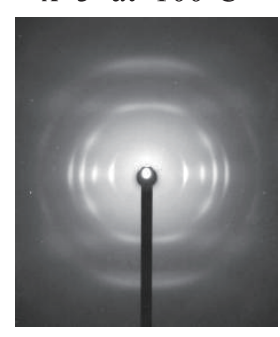

x 5 at $160^{\circ} \mathrm{C}$

Fig. 9 WAXD patterns of the annealed fibers previously drawn to 5 times at various temperatures.
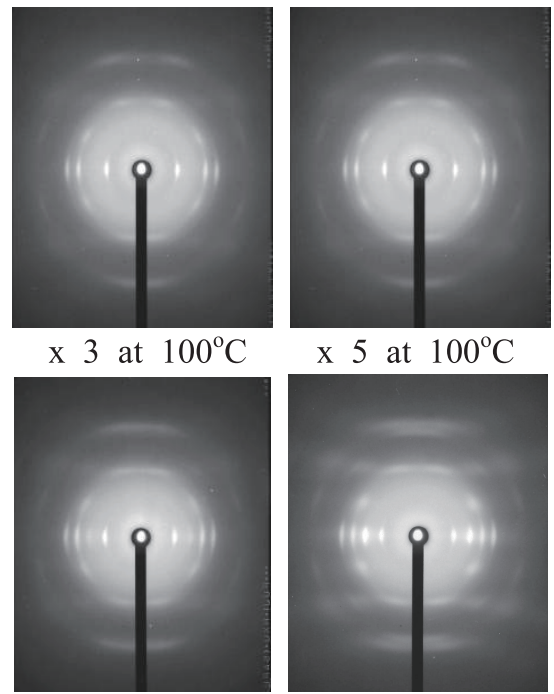

x 7 at $100^{\circ} \mathrm{C}$

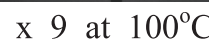

Fig. 10 WAXD patterns of the annealed fibers previously drawn to various ratios at $100^{\circ} \mathrm{C}$.
Appearance of two melting peaks of the homo-crystal observed at different temperatures indicates the two different states of the homo-crystal phase, one which easily transfers into the stereocomplex and the other which stays as a homo-crystal or transfers into amorphous phase. The fibers drawn to higher ratios at higher temperatures, which showed a large melting peak of the homo-crystal at higher temperature region, kept homocrystal phase even upon annealing at $200^{\circ} \mathrm{C}$. On the other hand, the fibers drawn to lower ratios at lower temperatures, which show the single melting peak of homo-crystal at a lower temperature region, changed the structure from oriented homo-crystal to the oriented stereocomplex upon annealing.

\subsubsection{Mechanical property of the annealed fibers}

Figs. 11(a) (c) show the changes in the mechanical property of PLLA/PDLA blend fibers upon annealing at $200^{\circ} \mathrm{C}$. These figures include the data for the as drawn fibers at $100^{\circ} \mathrm{C}$ to various ratios. It is clear that the tensile

(a)

(b)

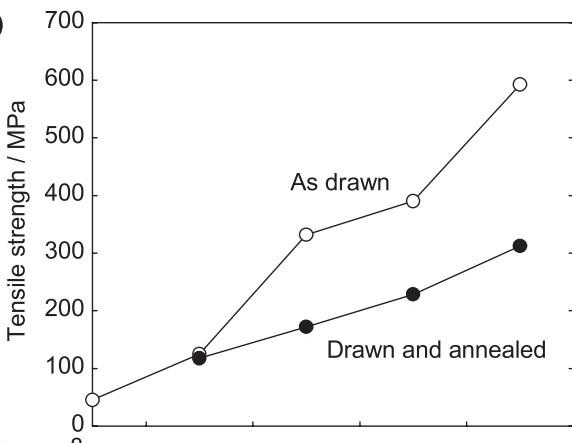

(c)
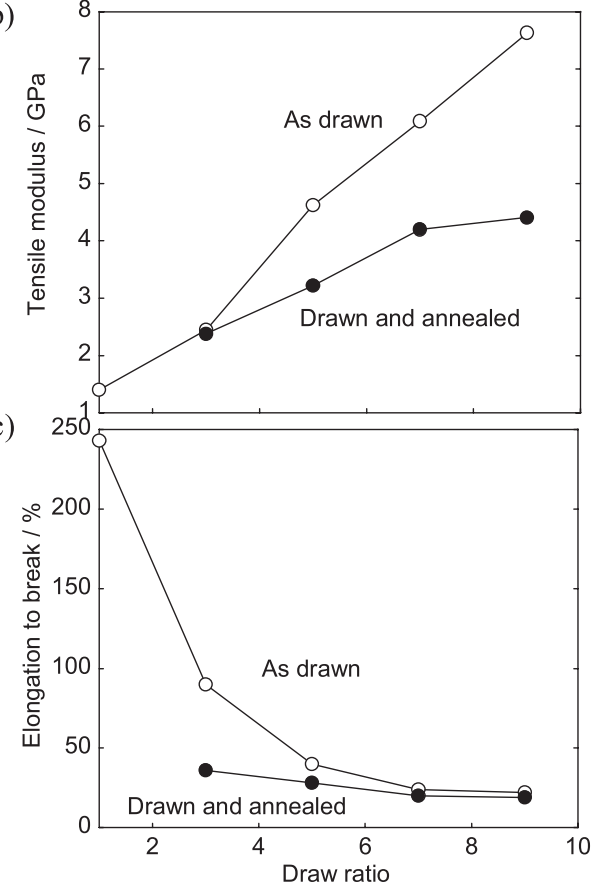

Fig. 11 Comparison of the mechanical property of as drawn and drawn and annealed fibers.

(a) Tensile strength, (b) tensile modulus, and

(c) elongationa to break. 
strength and modulus significantly deteriorated upon annealing at $200^{\circ} \mathrm{C}$, although the annealed fibers still kept their tendency that the higher the draw ratio, the higher the tensile strength and modulus. The elongation to break also reduced upon annealing. The WAXD patterns of the annealed fibers shown in Fig. 10 indicate the fairly high crystalline orientation. However as shown in Fig. 8, the DSC curves of the annealed fibers show a clear crystallization peak indicating that the annealed fibers have a low degree of crystal. Part of the homo-crystal phase transferred into the stereocomplex upon annealing without relaxing the crystalline orientation. However the rest of the homo-crystalline phase melted, relaxed and froze in an amorphous state upon annealing.

\section{Conclusions}

Solution-spun PLLA/PDLA blend fibers were obtained by the laboratory size spinning machine. The fibers obtained were drawn to various ratios at temperatures ranging from 80 to $140^{\circ} \mathrm{C}$ and subsequently annealed at $200^{\circ} \mathrm{C}$ under tension.

Solution-spun fibers were highly crystallized during the coagulation process in the solution spinning and only the $\alpha$-form homo-crystal of PLLA and PDLA were detected. Drawing of the fiber at temperatures between $80^{\circ} \mathrm{C}$ and $160^{\circ} \mathrm{C}$ did not promote the stereocomplexation between PLLA and PDLA. The drawn fiber seems to have two homo-crystal phases, one easily transformed to the stereocomplex upon annealing at an elevated temperature and the other stayed either homo-crystal or froze into the amorphous phase. Due to the low degree of oriented stereocomplex crystal and larger content of unoriented amorphous phase, the fibers annealed at an elevated temperature have a fairly poor mechanical property.

\section{References}

1. Y. Ikada, K. Jamshidi, H. Tsuji, S. H. Hyon, Macromolecules, 20, 904 (1987).

2. E. W. Fisher, Stersel, ; Wegner, H. J., Kolloid-Z. Z. Polymer, 251, 980 (1973).

3. H. Tsuji, Y. Ikada, Macromolecules, 25, 5719 (1992).

4. H. Tsuji, Y. Ikada, Macromolecules, 26, 691 (1993).

5. D. Brizzolara, H. J. Cantow, K. Diederichs, E. Keller, A. J. Domb, Macromolecules, 29, 191 (1996).

6. L. Cartier, T. Okihara, B. Lotz, Macromolecules, 30, 6313 (1997).

7. S. Baratian, E. S. Hall, J. S. Lin, R. Xu, J. Runt, Macromolecules, 34, 4857 (2001).

8. J. Penning, J. H. Dijkstra, A. J. Pennings, Polymer, 34, 942 (1993).

9. B. Eling, A. Gogolewski, A. J. Pennings, Polymer, 23, 1587 (1982).

10. J. W. Leenslag, S. Gogolewski, A. J. Pennings, J. Appl. Polym. Sci., 29, 2829 (1984).

11. I. Horacek, V. Kalisek, J. Appl. Polym. Sci., 54, 1751 (1994).

12. M. J. D. Eenink, J. Feijen, J. Olijslager, J. H. M. Albers, J. C. Rieki, P. J. Greidanus, J. Controlled Release, 6, 225 (1987).

13. M. Takasaki, H. Ito, T. Kikutani, J. Macromol. Sci., Part B, Phys., B42 (3\&4), 403 (2003).

14. H. Tsuji, Y. Ikada, S. H. Hyon, Y. Kimura, T. Kitao, J. Appl. Polym. Sci., 51, 337 (1994).

15. Y. Furuhashi, Y. Kimura, N. Yoshie, H. Yamane, Polymer, 47, 596 (2006).

16. D. Masaki, Y. Fukui, K. Toyohara, M. Ikegame, B. Nagasaka, H. Yamane, Sen'i Gakkaishi, 64, No.8, 212 (2008).

17. P. De Santis, A. J. Kovac, Biopolymer, 6, 199 (1968).

18. T. Okihara, M. Tsuji, A. Kawaguchi, K. Katayama, H. Tsuji, S. H. Hyon, Y. Ikada, Macromol. Sci., Phys., B30, 119 (1991).

19. Y. Ikada, K. Jamshidi, H. Tsuji, S. H. Hyon, Macromolecules, 20, 20, 904 (1987).

20. H. Tsuji, "Biopolymers" Vol. 4 (Y. Doi, A. Steinbüchel, Ed.), Wiley-VCH, Weinheim, p. 129 (2002). 